\title{
CONSEQUÊNCIAS ESPERADAS (E NEM TANTO) DO COVID-191
}

Espected consequences (and not even) of the COVID-19

\section{NASCIMENTO, Elimar Pinheiro do ${ }^{3}$}

\begin{abstract}
"So viel Wissen über unser Nichtwissen gab es noch nie" ("Nós não sabemos o suficiente sobre o nosso não-saber"), Jürgen Habermas em entrevista ao jornal Frankfurter Rundschau de 10 de abril de 2020.

"Nous ne savons pas ce se passe et c'est justement ce qui se passe" (Nós não sabemos o que está acontecendo e é isso exatamente o que está acontecendo), Edgar Morin, Paperback, april 12, 2018
\end{abstract}

\begin{abstract}
Despite some warnings, the COVID-19 pandemic came and caught countries and governments unprepared. A huge discussion was opened about its immediate and future, probable and possible consequences. The article summarizes part of this discussion that takes place through the media, social networks and academia, and that covers a wide range, from no significant changes to the end of capitalism. The consequences are divided between the visible impacts (on health, on the economy, on the spread of the use of TIs, on the increase of inequalities, on the technological race between the USA and China, on violence against women and on the strategic valuation of the health sector), probable (changes in urban configuration, reflux of globalization, retreat of the wave of far right and greater tension between the USA and China) and possible (growth of green parties, cooling of neoliberalism, greater relevance of initiatives for environmental preservation and valuation of social relations conviviality).
\end{abstract}

Keywords: COVID 19. Prospecting. Impacts. Global Changes.

Resumo: Apesar de alguns avisos, a pandemia do COVID-19 veio e pegou países e governos despreparados. Uma imensa discussão foi aberta sobre as suas consequências imediatas e futuras, prováveis e possíveis. 0 artigo resume parte desta discussão que se faz por meio da mídia, das redes sociais e na academia, e que recobre um amplo leque, desde nenhuma mudança significativa até o fim do capitalismo. Divide-se as consequências entre as visíveis (impactos na saúde, na economia, na disseminação do uso das Tis, no aumento das desigualdades, na corrida tecnológica entre EEUU e China, na violência sobre as mulheres e na valoração estratégica do setor de saúde), prováveis (mudanças na configuração urbana, refluxo da globalização, recuo da onda de autocratização e maior tensão entre EEUU e China) e possíveis (crescimento dos partidos verdes, arrefecimento do neoliberalismo, maior relevância das iniciativas de preservação ambiental e de valoração das relações sociais de convivialidade).

Palavras-chaves: COVID-19. Prospecção. Impactos. Mudanças globais.

\footnotetext{
${ }^{1}$ Recebido em: 15 Ago. 2020 | Aceito em: 30 Ago. 2020.

${ }^{3}$ Sociólogo político e socioambiental e Professor da Universidade de Brasília/UnB e dos Programas de PósGraduação - Desenvolvimento Sustentável/UnB e Ciências Ambientais e Sustentabilidade na Amazônia/UFAM. elimarcds@gmail.com
} 


\section{INTRODUÇÃo}

Nossas redes sociais, jornais, revistas, blogs estão repletas de informações e reflexões sobre o fenômeno da pandemia provocada pelo novo coronavírus, SARS-COV-2, a doença infecciosa COVID-19. São informações úteis, e outras duvidosas, de como podemos nos proteger melhor, o que devemos fazer para sairmos melhor desta pandemia.

Não há uma pandemia, mas diversas. Os humanos vivem situações muito diferentes. Alguns têm depressão e ansiedade. Outros conhecem a perda de familiares, amigos e colegas ou perdem seus empregos e rendas. Outros conhecem situações de tensões, trabalhando nos centos de saúde que tratam dos infecionados. Situações que mudam em conformidade com as condições genéticas, psíquicas, etárias e socioeconômicas dos humanos. Que mudam segundo o país e a cultura, a situação social concreta vivenciada e as obrigações e demandas de cada um. Múltiplas pandemias.

As reflexões dos meios de comunicação discorrem também sobre a criação de vacinas, para neutralizar a transmissão da doença e de remédios para neutralizar seus efeitos, em alguns casos mortais. A mídia fala de mais de 250 laboratórios, empresas e centros de pesquisa envolvidos no processo de descobrir/criar uma vacina eficaz e sem efeitos colaterais sérios à saúde humana. Pelo menos cinco dessas experiências já se encontram em estado avançado de teste, ou seja, envolvendo grupos significativos de humanos em distintos países. Há mesmo notícias de que se teria uma vacina pronta antes do fim do ano. No caso, uma vacina em experimentação na Rússia, embora não exista publicações em revistas científicas que atestem sua veracidade, segurança e eficácia (G1, 03/08/2020). Mas chineses, americanos e ingleses também estão prometendo uma vacina entre dezembro/2019 e janeiro/2020. Temos que aguardar.

Os vírus existem na face da terra aos milhares. Seres minúsculos, a maioria é apenas observável com microscópios eletrônicos, inventados nos anos 1930. Não são considerados organismos, pois não apresentam o material bioquímico necessário para reproduzir sua energia metabólica. Por isso, necessitam de outros seres vivos para se reproduzir. São, assim, parasitas intracelulares. Uma vez dentro da célula de um ser vivo são capazes de se reproduzir com velocidade extraordinária. Sobre a origem do SARSVOC-2 ainda não existe um consenso na literatura científica (SANJUAN et al., 2010). 
O conhecimento sobre o comportamento do coronavirus SARS-COV-2 é ainda precário, apesar de crescente a cada dia. Embora, ainda neste século, tenham-se registros de endemias provocadas por vírus da mesma família em 2002/2003 e 2012/2013, não se tem clareza suficiente sobre a sua transmissibilidade, letalidade e imunidade. Há dúvidas múltiplas como o vírus ataca o aparelho respiratório dos humanos, inclusive se os que já foram infectados tornam-se imunes. Há poucos indícios contrários.

No início, muitas das reflexões publicizadas dirigiam-se para entender a origem da disseminação do vírus. O presidente dos Estados Unidos, com evidente interesse político em ano eleitoral, lançou uma versão sobre a origem da transmissão do vírus nos humanos. Trump sugeriu a origem laboratorial do vírus, por acidente de trabalho ou intenções perversas, na China. Artigo publicado por Andersen et al. (2020) apresenta vários indícios da inconsistência desta versão, que se contrapõe a mais aceita, de transmissão do vírus aos seres humanos a partir de animais selvagens, provavelmente o morcego, intermediado ou não por outro animal antes de alcançar os humanos, por meio do "transbordamento zoonótico" (FioCruz, 2020). Tudo tendo ocorrido na cidade de Wuhan, na China, cujos primeiros sinais datam de dezembro de 2019. A descoberta da infecção foi feita em um paciente internado em 12/12/2019 (Alves, 2020).

Mas, o debate que nos interessa neste artigo versa sobre as consequências da pandemia sobre os destinos dos humanos. Mais precisamente, o artigo é tecido pela pergunta de quais são as consequências da COVID-19. Tanto aquelas imediatas, visíveis desde já, até aquelas de menor visualização, ou seja, aquelas apenas perceptíveis e, por isso mesmo, duvidosas. Portanto, consequências certas (óbvias), prováveis e possíveis.

\section{DESENVOLVIMENTO}

\subsection{Risco e atração inevitáveis da prospecção}

Antes de sinalizar as consequências identificáveis hoje da COVID-19 são necessárias duas palavras acerca da arte ou ciência da prospecção. Prospectar é sempre uma atividade arriscada. 0 mundo humano é muito complexo, talvez mais do que o mundo 
natural. As variáveis são quase infinitas, suas combinações e desdobramentos incomensuráveis. Por mais que conheçamos as variáveis do presente e as técnicas de prospecção, como recorda Taleb (2008), sempre pode surgir um cisne negro, um evento inesperado que muda tudo, desenha possibilidades não imagináveis, configura situações imprevistas. No entanto, os homens insistem e persistem na tentativa de visualizar o porvir. Desde tempos imemoriais. E com técnicas as mais variáveis, desde o Tarô até as técnicas sofisticadas de modelagem matemática de cenários.

O uso da prospectiva persiste entre os humanos porque ela permeia a nossa vida mais do que imaginamos. Ela não é apenas uma tentativa de imaginar ou conceber o futuro, de forma diletante. Ela é indispensável para tomarmos decisões hoje, sobre nossas vidas amanhã. De certa forma, sem uma visão de futuro não temos presente. A prospectiva nos acompanha no dia a dia. Um exemplo simples e banal: quando vamos atravessar uma rua que não tem semáforo e possui um trânsito razoável, fazemos o exercício da prospectiva: "calculamos" a velocidade dos veículos e o tempo que tomaremos na travessia, para decidir o momento seguro de atravessar a rua. Se erramos....

Por isso, fazer um desenho das prováveis consequências da atual pandemia é tarefa arriscada, mas atraente. Arriscada porque, entre outros, ela se encontra ainda em pleno curso, com duração imprevisível. Aparentemente, será necessária uma vacina para encerrá-la, embora casos similares, anteriormente registrados na história da humanidade, mostrem que é também possível seu encerramento sem a vacina. Porém, com custo altíssimo, pois teria que ocorrer o que se denomina habitualmente de "imunidade por rebanho", ou seja, o encerramento da circulação do vírus por dificuldade de encontrar hospedeiros. Um alerta, nesses casos o ressurgimento é sempre possível. Acrescente-se a isso o desconhecimento sobre o comportamento do coronavirus SARSCOV-2. Mesmo a imunização dos infectados não é de toda assentada no conhecimento médico atual, nem o percentual das pessoas que teriam defesas naturais contra o vírus. Dúvidas, muitas dúvidas, inclusive no caso da vacina, pois segundo noticias da OMS, em junho existiam 133 estudos em andamento (O Globo, 09/08/2020). Destes, 42 se desenvolvem nos Estados Unidos e 19 na China, com cinco já em fase de testes avançados nos humanos.

Segundo a mesma fonte, o estudo mais avançado seria aquele desenvolvido pela Universidade de Oxford, no Reino Unido. Não se deve, porém, ter-se espanto se os 
chineses surpreenderem, chegando primeiro. As tecnologias utilizadas na produção da vacina são distintas, com novidades nesses processos. Em qualquer caso, porém, a tarefa é hercúlea: teste, comprovação, produção, distribuição e aplicação da vacina em bilhões de pessoas. Quantos meses serão necessários para que os humanos estejam imunizados? Não se sabe: julho de 2021, novembro de 2021, abril de 2022 ?

Caso se confirme a temporalidade além de um ano (a OMS prevê 18 meses, julho de 2022), até que todas as pessoas tenham coragem de sair de casa, sem maiores constrangimentos, hábitos podem ser modificados. E, portanto, novos comportamentos e percepções podem surgir. Quais? Outra incógnita. $O$ fato é que se encontra disseminada uma grande expectativa de mudança, com ou sem razão.

Por isso mesmo, o mundo inteiro debate sobre a época pós-pandemia, com visões diversas e antagônicas. E tem suas razões, afinal é o acontecimento mais trágico que se conhece desde a Segunda Guerra Mundial. André Magnelli (2020) identifica que "hay una ansiedad generalizada de volver a la normalidade". Os mais pessimistas acreditam que a única aprendizagem dos humanos será a de lavar as mãos. Jaime Pinsky afirma em artigo no Correio Brasiliense (02/08/2020) que "nada, nadinha irá mudar".

No outro extremo há os que perspectivam mudanças radicais, pois o modelo econômico vigente estaria em queda livre. Agamben (2020) acredita que a pandemia é uma invenção do capitalismo, Žižek (2020), mais radical, afirma que:

Mi modesta opinión es mucho más radical: la epidemia de coronavirus es una especie de ataque de la "Técnica del corazón explosivo de la palma de cinco puntos" contra el sistema capitalista global, una señal de que no podemos seguir el camino hasta ahora, que un cambio radical es necesario.

A crise do capitalismo é uma das expressões mais usuais hoje em dia. Aliás, é uma expressão que escuto há 60 anos, e sobre as quais tenho lido rastros desde o século XIX. Przeworski (2020) cita que na biblioteca de Widener em Harvard existem 23.600 livros em inglês publicados no século XX, com a palavra crisis. 0 que me dá a sensação de que crise é o modo de existência do capitalismo, e não um evento extraordinário. Há mesmo quem afirme que estamos em vias de uma mudança civilizacional, que seria acelerada pela covid 19. É possível, mas mudanças civilizacionais demandam décadas senão séculos. 
Neste caso, seria um pequeno empurrãozinho. Por esta razão evita-se aqui falar de crise sanitária, econômica, política e social, como muitos a fazem.

El País (2020), entre outros jornais, consultou 75 pensadores a respeito dos desafios e das consequências da COVID 19, apresentando um mosaico curioso e divergente. 0 leque é vasto, e sortido, como redução de conflitos, vida mais simples, valorização da vida em comum, recuperação dos vínculos intergeracionais, revalorização da nutrição saudável, maior relevância das empresas nacionais, centralidade das TI, redução de atividades como o turismo, mais voz aos trabalhadores, aumento da noção da finitude dos recursos naturais, fortalecimento da governança global, aceleração da decadência do Ocidente, entre outros. Na maioria das vezes as pessoas manifestam mais o seu desejo do que as tendências prováveis, ou aquilo que elas observam ao seu redor ou experimentadas pessoalmente.

Para fins didáticos apresentaremos as consequências em uma ordem da mais óbvia a menos notória. Evidentemente que a lista não é exaustiva, mas tenta detectar as que parecem mais relevantes, no dia de hoje, segundo consta na maioria dos veículos de informação disponíveis na web. Com um olhar claramente brasileiro. Pessoas de outras nacionalidades devem encontrar pontos em comum, mas também muitas diferenças.

Um último esclarecimento. A pandemia impacta diferentemente os diversos países, e neles, os seus distintos segmentos sociais. Em alguns países ocorreu um isolamento social mais ou menos bem observado, em outros o isolamento social, como no Brasil, foi mais um faz de conta, raramente mais da metade da população estava realmente em casa. Em outros, não ocorreu isolamento social nenhum, o governo apenas recomendou cuidados aos seus cidadãos. Em todos, os profissionais da saúde e trabalhadores de atividades essenciais viveram ou vivem uma experiência estressante; tiveram que sair e se expor diuturnamente.

Os que ficaram em casa tiveram experiências muito distintas. Algumas ficaram desesperadas, como mães solteiras, obrigadas a fazer home office, com filhos pequenos em casa, e sem apoio. Outros ficaram em casa, sozinhos, em habitações pequenas, tendo ansiedade e depressão. Enfim, as situações são as mais diversas e, por isso, não se pode fazer afirmações genéricas. Afirmar que as pessoas vão parar de consumir só pode ser verídico para quem tem boa renda, e o hábito de consumir desmesuradamente. 
Corresponde a quanto? A 0,1\% da população? Por isso, todas as afirmações a seguir devem ser consideradas com parcimônia e o devido cuidado, elas não refletem as diversas situações concretas em que vivem os humanos, mas aquelas que são amplamente manifestas nos veículos de informação digital.

\subsection{Consequências visíveis e óbvias da COVID-19}

Há consequências óbvias, como o alto e crescente número de óbitos, que caminha vagarosa, mas imperturbavelmente, para a casa do milhão. É provável que em setembro este número seja superado. No dia 06 de agosto de 2020 eram 706.342 óbitos no mundo, dos quais 97.418 no Brasil ${ }^{4}$.Uma surpresa para quem a imaginava uma "gripezinha".

Observe-se que a pandemia se dirige a outras regiões ainda pouco afetadas, com numerosa população de pobres e sem estrutura adequada de saúde pública. Sem contar a possibilidade de reincidência em alguns países, inclusive asiáticos, como a China. Esses eventos já tornaram esta pandemia a maior dos últimos cem anos, ou seja, após a gripe espanhola que matou, segundo os veículos de informação, entre 20 e 100 milhões de pessoas no começo do século XX (Biblioteca Fio Cruz, 2020). A única concorrente seria a AIDS, que já matou cerca de 35 milhões de pessoas, desde $1981 .^{5} \mathrm{E}$ para a qual não se conhece ainda uma vacina, mas já há medicamentos relativamente eficientes. Porém, a AIDS e a COVID-19 não podem ser comparadas, tendo em vista as suas profundas diferenças. Em particular quanto a forma de transmissão de uma e outra doença. No primeiro caso, os humanos têm a opção de evitar a doença, salvo a transfusão de sangue, porque ela demanda uma decisão de risco pelo contaminado, na medida que a transmissão se faz pelo ato sexual sem prevenção. No segundo caso, as variáveis estão relativamente fora do controle do indivíduo, a transmissão se faz pelo ar ou contato com algo, pessoa ou objeto pela mão, depois levada a boca, nariz ou olhos. Sem qualquer visibilidade ou sensibilidade do tato. Por isso, o isolamento social aplicado pela esmagadora maioria dos países no combate a COVID-19. 0 que não foi necessário no caso

\footnotetext{
${ }^{4}$ Este link apresenta de forma atualizada os infectados pela COVID-19 e os óbitos no mundo no Brasil https://news.google.com/covid19/map?hl=pt-BR\&gl=BR\&ceid=BR:pt-419

5 Disponível em: https://www.msf.org.br/o-que-fazemos/atividades-medicas/hivaids\#: :text=3,HIV\%2FAids,novos $\% 20$ casos $\% 20$ todos $\% 20$ os $\% 20$ dias.
} 
da AIDS, substituído por campanhas de informação quanto as medidas de prevenção. Por outro lado, a mortandade neste caso ocorreu, em grande parte, nos países que não adotarem medidas preventivas por razões religiosas ou outras.

O mais grave, porém, é que outras pandemias poderão advir. Seja pela continuidade da agressão à natureza que realizamos, seja pelo desgelo dos polos, seja por um acidente de trabalho em algum dos laboratórios que trabalham com vírus no mundo, ou seja, por uma ação terrorista. Os polos são um museu da história da natureza e das origens da humanidade e, por isso mesmo, eles guardam bactérias e vírus que já atingiram os humanos, entre os quais a gripe espanhola. Quais destes vírus retornarão a nos visitar em tempos breves, a continuar o aquecimento global? A próxima pandemia poderá nascer, inclusive, na Amazônia, onde se pratica um crime ambiental com o desmatamento crescente.

Uma segunda consequência notória é o desastre econômico resultante da paralisação das atividades econômicas não essenciais, durante meses. E, na maioria dos países, de forma generalizada ou regionalizada. Mesmo o moderado FMI reconhece que o "panorama externo é altamente incerto" (Kaufman e Leigh, 2020). Desconhece-se qual o tempo necessário para a recuperação da economia mundial. As previsões de queda econômica variam em torno de $6 \%$ ou mais, na maioria dos países afetados. Os últimos dados mostram uma queda, no segundo trimestre, de mais de 10\% do PIB na Alemanha e 9,5\% nos Estados Unidos. O FMI calcula uma perda mundial acumulada do PIB da ordem de US\$ 9 trilhões (LEITÃO, 2020). A CEPAL considera que a AL entra na "recessão mais abrupta de sua história". Neste continente, a queda média do PIB deve ser da ordem de 9\%, o desemprego deverá chegar a 13,5\% e a pobreza deve alcançar $37,3 \%$ da população. ${ }^{6}$

As falências, o desemprego e a perda de renda estão ocorrendo em tal magnitude que serão necessários alguns anos para que ocorra um retorno ao nível anterior. Nos EEUU a taxa de desemprego está em torno de 14\%, ou seja, 20 milhões de trabalhadores, embora alguns economistas prevejam a recuperação em V. Há, no entanto, sinais que indicam o contrário. A OCDE prevê para a União Europeia uma taxa de desemprego em torno de $10 \%$, quando se encontrava em torno de 3,5\% em 20197 . Contudo, não se pode

\footnotetext{
${ }^{6}$ El Pais, 31/07/2020.

7 https://data.oecd.org/fr/unemp/previsions-des-taux-de-chomage.htm. Acesso em: 30 jul. 2020.
} 
esquecer, a economia é um dos campos do conhecimento humano que menos avançou na capacidade de previsão, segundo Silver (2013). 0 mais frequente é as previsões iniciarem o ano otimista e, pouco a pouco, elas tornam-se piores.

Assim, a fome, a pobreza e a desigualdade estão crescendo em praticamente todos os países. Com algumas surpresas, como as filas para receber alimento na Suíça. Isso mesmo, na Suíça, um dos paraísos dos países desenvolvidos. E, em Nova York, a capital do capitalismo. Aproximadamente metade da população mundial vive com menos de 5,5 dólares por dia. ${ }^{8} \mathrm{~A}$ tendência é a situação tornar-se mais crítica.

0 fato é que o mundo se desenha mais desigual e mais perverso para boa parte das sociedades no Pós-COVID-19. Desigualdade que deve crescer também entre países. A China e alguns países asiáticos, como a Coreia do Sul, devem ganhar mais relevância econômica e tecnológica. Foram os países que melhor, e mais rapidamente, responderam a pandemia, recuperando-se economicamente antes que qualquer outro (Chernilo, 2020). Por sua vez os Estados Unidos, o México e o Brasil responderam desorganizadamente e deverão pagar por estes erros. Assim, a América Latina, deverá se tornar mais pobre. As debilidades econômicas norte-americanas devem aumentar, em favor de seu principal concorrente, os chineses, que cresceram 3,5\% no segundo trimestre. Estes eventos confirmam a tese de Kai Fu Lee (2019) de que os chineses têm mais instrumentos para aproveitar da Inteligência Artificial (IA) e crescer com mais vigor.

Para manter a dianteira na corrida tecnológica, particularmente no campo da Inteligência Artificial (IA), os Estados Unidos necessitam de novas descobertas, pois no campo da aplicação das tecnologias já conhecidas os chineses estão tomando a dianteira com seu exército de engenheiros, empreendedores digladiadores e uma batelada de dados. Quantidades que os americanos não têm. Estes podem se posicionar na frente por meio de novas invenções disruptivas, também em outros campos, como por exemplo, no campo da energia, como o controle da fusão nuclear (Rincon, 2020). Outro risco para os chineses ocorrerá se novas invenções foram descobertas no âmbito fechado das grandes companhias, como o Google, que investem em IA mais do que o governo americano.

\footnotetext{
${ }^{8}$ Disponível em: https://www.oxfam.org/fr/cinq-faits-choquants-sur-les-inegalites-extremes-aidez-nousredistribuer-les-cartes, Acesso em: 30 jul. 2020.
} 
Outro campo importante de mudança provável está ocorrendo no setor da saúde. Segundo seus profissionais, as enfermidades psíquicas crescem, como a depressão e a ansiedade, resultantes do isolamento social e do clima de medo que se instalou na maioria das sociedades. E aumenta a insegurança, porque não se sabe sobre a trajetória futura da pandemia. Quando será produzida uma vacina eficiente? Não se sabe. Ninguém sabe. E este desconhecimento afeta as pessoas do ponto de vista psíquico, em particular as crianças (Linhares e Florim, 2020). Como elas processarão esta experiência traumática ao longo de suas vidas?

Crescem, também, as violências domésticas e os distúrbios infantis. Neste caso, embora as crianças tenham pouca probabilidade de contrair a COVID-19, e menos ainda de terem sintomas graves ou óbito, não estão imunes a quadros de ansiedade e depressão com o isolamento social. Porém, depende de situações concretas. Algumas, inclusive, sentem-se melhor com a presença dos pais e sem a pressão das escolas. Outras sofrem não apenas estados de ansiedade, mas também a violência doméstica de pais repressivos e violentos (Menezes, 2020). No caso das violências sobre as mulheres a tendência, com a pandemia é aumentar. 0 Brasil é conhecido como um dos países de maior índice de feminicídio. Uma mulher é morta a cada sete horas. Em 2019 foram 1314 (Sampaio, 2020). Não se tem dados nacionais, mas sabe-se, que no final de março havia, no Rio de Janeiro, um aumento de 50\% (Nascimento, 2020).

Os serviços de saúde e a indústria farmacêutica, se já eram importantes, tornaramse estratégicos para as Nações. Teme-se que novas pandemias aflorem e o risco de ficar dependendo de outros países é muito custoso, inclusive em vidas humanas. Assim, os Estados Nacionais, sobretudo os de países desenvolvidos ou em desenvolvimento, devem investir mais nesse setor, na prevenção e no atendimento, mas também nas pesquisas.

Consequências outras estão também em curso, como o fortalecimento da Tecnologia da Informação, por meio da difusão das diversas atividades que elas oferecem e que ganham mais relevância durante a pandemia, como o home office, o aceleramento do ensino a distância, a disseminação das videoconferências para palestras, debates e reuniões, a maior relevância do e-comércio e dos serviços de delivery. A web ganhou segmentos sociais que antes lhe eram avessos. Professores, servidores públicos, empregados de empresas privadas, donas de casa e idosos, entre outros, aprendem a manejar as novas ferramentas de TI. Setores do serviço público e de empresas privadas 
percebem que, em algumas situações, o home office é mais produtivo; entidades de ensino percebem que o ensino a distância é mais rentável. Essas mudanças que estão ocorrendo devem configurar novas situações no mundo do trabalho.

O fortalecimento dessas tecnologias tem repercutido no crescimento das grandes empresas do setor como Amazon, Google, Appe, Microsoft, Facebook, Samsung, Alibaba, Tecent, Baidu. Mas também em empresas menores e que cresceram extraordinariamente durante a pandemia como Zoom Us e a Bytedance, dona da Tik tok. A Zoom tinha 2 milhões de clientes em 2019, hoje tem mais de 300 milhões. Enquanto perdem emprego ou renda, outros como o proprietário da Zoo US, Eric Yuan, torna-se bilionário.

\subsection{Consequências prováveis}

Haverá, provavelmente consequências diversas no espaço urbano. 0 refluxo da mobilidade urbana e o aumento do e-comércio, somado às novas tecnologias de trânsito, tornarão a circulação de veículos mais inteligente, mais confortável e mais rápida. Com a contrapartida da tendência de evitar transportes urbanos com muita aglomeração, deverá ocorrer uma valorização do ato de morar perto do trabalho. O "sem transporte" (caminhada), poderá crescer em cidades em que este procedimento for possível adotar. Mas, qual a mudança dominante? O uso de bike cresce e o de veículos particulares crescerá também, com riscos no uso de transporte público? Pelo menos em algumas cidades, e em alguns segmentos sociais, mudanças ocorrerão, noutras, porém, como cidades tropicais, e de muita pobreza, as mudanças serão quase que imperceptíveis. A maioria dos trabalhadores não tem condições de adquirir veículos próprios e o uso da bike, em algumas situações, é inviável.

De toda forma, é possível que uma tendência de redução dos grandes aglomerados, débil ainda em algumas partes do mundo, venha a se acelerar. Um processo de desmigração urbana, que a pandemia apontou, poderá vir a se configurar, em favor das cidades pequenas, médias e de espaços semiurbanos. Além do que, se espera, deverá haver uma mudança no papel das grandes cidades, sem que se tenha uma ideia precisa da mudança vencedora: "O desafio se configura em tentar entender que comportamentos ou 
cenários serão refeitos e que mudanças as nossas cidades apresentarão após esta experiência global" (Bezerra e Cunha Junior, 2020).

Outras tendências anteriormente existentes como o das redes sociais ocuparem o lugar da imprensa tradicional, de jornais e revistas, na veiculação de informações, estão sendo aceleradas. 0 que tem obrigado, estes, a migrarem para o espaço da web com mais rapidez. 0 jornal de papel já estava se transferindo para os museus, e a pandemia acelerou o processo.

A nova internacionalização da economia, que recebe o nome de globalização, parece conhecer um refluxo. A circulação de bens e serviços na economia mundial tende a se arrefecer, enquanto o nacionalismo e a xenofobia, emergentes nas últimas décadas, se fortalecem. Com isso, o protecionismo deve crescer. Novos muros deverão ser erguidos, e a perseguição aos imigrantes deve aumentar. 0 mundo deverá estar mais fechado amanhã. A livre circulação de informações, que já conhece restrição em várias partes do mundo, deve sofrer um impacto desastroso do ponto de vista democrático ${ }^{9}$.

Vai facilitar o recuo da globalização o fato de que as viagens longas devem retornar com parcimônia, pois durante algum tempo serão vistas com desconfiança. 0 turismo, uma das atividades econômicas de maior crescimento nos últimos vinte anos, tende a refluir, com a valorização dos locais mais pertos e mais seguros, com menos fluxo de pessoas. Segundo a FGV 93\% dos serviços da cadeia de turismo foram afetados. A perda econômica estimada no Brasil é da ordem de R 116 bilhões, e serão necessários mais de 12 meses para a recuperação do setor (FGV, 2020).

A tendência do aumento das tensões entre China e Estados Unidos cresceu com a pandemia, mas antes já vinha crescendo com as mudanças ocorridas nos últimos anos na direção dos respectivos países, a ascensão de Trump (2017) e Xi Jinping (2013). Os Estados Unidos fecharam o consulado chinês em Houston, e a China respondeu fechando o consulado americano em Chengdu. Trump ameaçou expulsar o aplicativo Tik tok dos Estados Unidos até o dia 15 de setembro se ele não for vendido a uma empresa norteamericana. De propriedade da empresa chinesa Bytedance, o aplicativo tem mais de 80 milhões de usuários nos Estados Unidos. A empresa chinesa, Huawei, uma das

\footnotetext{
9 https://www.sul21.com.br/opiniaopublica/2020/04/pandemia-e-globalizacao-o-que-esperar-dos-
} proximos-anos-por-luiz-marcelo-michelon-zardo/ acessado em 06/08/2020. 
especialistas em internet 5 G, já tinha sido banido dos Estados Unidos o ano passado. A tensão de Trump com a China, portanto, apenas foi acelerada com a pandemia, pois a perda de intenção eleitoral do presidente norte-americano levou-o a realçar sua resistência aos produtos chineses, como forma de recuperar a popularidade. Provavelmente esta tensão prosseguirá no caso de Trump perder as eleições, porém de forma menos agressiva.

Surpreendentemente, a pandemia está contribuindo para o recuo da extrema direita no mundo, ou seja, parece que se ergueu um muro contra a expansão do populista autoritário. Nos Estados Unidos, a popularidade de Trump aos poucos se desfaz, permitindo ao seu adversário uma diferença de mais de dois dígitos. Na França, a extrema direita ficou reduzida a pouco mais de uma única municipalidade relevante, Perpignan, dentre as cerca de 35 mil que detém ao país. Na Alemanha, o prestígio das forças de centro cresce no seio da população. No Brasil, a popularidade de Bolsonaro recuou no primeiro momento, recuperada graças a verba de auxílio aos necessitados, alimentado por sua mudança de estratégia política de parar a hostilidade aos Poderes Constitucionais e aproximação com o Centrão. Mas, esta verba não deverá se prolongar até 2022, sob pena de se desfazer sua política econômica neoliberal e perder uma das medalhas do seu ministério, o "posto Ipiranga”, Paulo Guedes.

\subsection{Consequências possíveis}

Há expectativa de mudanças políticas no âmbito dos países europeus. A vitória dos verdes, nas eleições municipais na França, é um sinal de que populações buscam outras políticas públicas. Sobretudo que o grande derrotado foi o largo espectro das forças de direita, de Macron a Le Pen, passando pelos republicanos. Aparentemente, há uma demanda de novas políticas que preservem o meio ambiente sem destruir os empregos e a renda dos mais pobres e, como também, da classe média.

Essa atitude soma-se a maior importância dos resguardos relativos à sustentabilidade atribuída pela classe empresarial no ano passado na reunião de Davos. E que aparentemente se agudizou com a pandemia atual. Acrescente-se a declaração dos 
90 milionários que clamaram a seus governos a aumentar os impostos sobre as suas fortunas, no documento denominado "Milionários pela Humanidade" (Sakamoto, 2020). Mas, segundo Veiga (2020), a

recuperação econômica sustentável não virá de medidas fiscais de curto prazo. Só reformas de cinco a dez anos de duração poderão favorecer arranjos econômicos de baixo carbono no pós-pandemia. Este é o reparo e alerta do maior especialista em Global Green New Deal, o professor da universidade estadual do Colorado (EUA) Edward B. Barbier.

Não se pode negar que o modelo econômico está sendo posto em questão de forma mais incisiva. Há um maior número de críticas, e de críticos. Há muita retórica, mas resta dúvida, porém, se o neoliberalismo tem seus dias contados, na medida em que a relevância do papel do Estado voltou à ordem do dia. A disponibilização de um montante superior a 700 bilhões de euros pela União Europeia para combater a crise econômica é um sinal de que o Estado é parte fundamental na recuperação econômica. Mas não haverá, provavelmente, um retorno ao velho keynesianismo. A dúvida nasce do fato de que durante a crise 2008/2009 também o Estado desempenhou um papel importante, nem por isso o neoliberalismo foi enterrado. Continuou sua trajetória descendente, mas de forma parcimoniosa. E é este o passo que deverá se manter. Mais ainda, deve-se desconfiar de mudanças substantivas na economia de mercado.

Em épocas de tensionamento emergem visões mais pessimistas sobre o futuro da humanidade, e mesmo catastrofistas, como a mais recente, a de David Wallace-Weells (2019). Bologna e Aquino (2020) apontam no mesmo sentido em artigo recente na Nature.

Há uma expectativa de mudanças, de novas iniciativas fora da economia dominante. Livros, artigos acadêmicos e de opinião em periódicos e blogs no mundo inteiro são produzidos e publicizados em quantidade inimaginável. Edgar Morin acaba de publicar seu mais novo livro - Changeons de voie (Mudemos de caminho). O sucesso de Kate Raworth (2019), com seu livro, publicado no Brasil sob o título de A economia Donut, é extraordinário. Um dos maiores estudiosos do turismo sustentável, Richard Sharpley 
(2020), defende hoje o decrescimento. Foi surpreendente a repercussão da declaração, singela, dos 170 acadêmicos da Holanda ${ }^{10}$. Em toda parte, há sinais de mudança. No Brasil, ex-ministros da economia e presidentes do Banco Central no Brasil se manifestaram de forma surpreendente, e mesmo contraditória com suas posições anteriores (Martelo, 2020).

\section{CONCLUSÃO}

No quadro que traçamos há consequências óbvias, como o impacto sobre o número de óbitos, a perda de dinamismo econômico, o aumento das desigualdades, da fome e da pobreza. Como também o ganho de relevância das TIs, do setor de saúde e de formas de deslocamento, e a perda de ritmo da expansão das autocracias e do movimento de globalização.

Contudo, há consequências que são menos previsíveis, sobretudo, se virão ou não a se firmar. Uma, entre tantas outras possíveis, é o fortalecimento de movimentos culturais e sociais como o ambientalismo, o decrescimento e o convivialismo. Aparentemente, alimentados pela maior consciência do valor da natureza e sua preservação, assim como, do valor de novas relações sociais, de solidariedade.

Os cientistas sociais e ambientais têm um papel de maior relevância na nova conjuntura. De um lado, revelando melhor as suas consequências e magnitudes, como o crescimento da desigualdade social, interna e entre países; das diversas formas de violências, sobre as mulheres e as crianças; do crime organizado, adentrando nossas instituições politicas e do risco do descontrole das empresas de alta tecnologia. De outro lado, o papel de revelar para o mundo as pequenas experiências de busca de novos padrões de produção e consumo, assim como, sobre a ainda pena disseminação de experiências de novos estilos de vida. Os cientistas socioambientais devem tomar a séria a possibilidade outra economia, de outro estilo de vida em melhor conformidade com a natureza.

10 Disponível em: https://climainfo.org.br/2020/04/28/academia-holandesa-propoe-decrescimentosustentavel. Acesso em: 01 ago. 2020. 
Há uma sensibilidade crescente, agudizado pela pandemia, de políticas que preservem a natureza, reduzam a desigualdade e eliminem a extrema pobreza, com pressões sobre o papel do Estado. Porém, não se sabe a profundidade, a repercussão e o desdobramento dessas mudanças, numerosas e pequenas. Aparentemente, sem força para produzir mudanças estruturais. Resta a esperança de que, por vezes, grandes movimentos nascem de pequenas iniciativas. Segundo a "lenda", maio de 1968 iniciou-se em uma sala de aula da Universidade de Nanterre, onde era professor Manuel Castells e aluno, Daniel Cohn-Bendit.

\section{REFERÊNCIAS}

ALVES, Rafael. (2020) Tudo sobre o coronavirus covid 19: da origem à chegada ao Brasil. Estado de Minas, 27/02. In https://www.em.com.br/app/noticia/nacional/2020/02/27/interna nacional,1124795 /tudo-sobre-o-coronavirus-covid-19-da-origem-a-chegada-ao-brasil.shtml. Acesso em: 30 jul. 2020.

AGAMBEN, Giorgio (2020). La invención de una epidemia. In: Sopa de Wuhan: pensamiento contemporaneo en tiempos de pandemias In Giorgio Agamben et al. Editorial ASPO (Aislamiento Social Preventivo y Obligatorio); 2020. 188 p. https://bit.ly/sopadewuhan.

ANDERSEN, Kristian G; RAMBAULT, Andrew; LIPKIN, W. Ian; HOLMES, Edward C. e GARRY, Robert F. (2020) The proximal origin of SARS-COV-2. Naturemedicine, 26, 450452.

BBC. Eric Yuan, o bilionário criador do zoom que viu sua riqueza se multiplicar durante a pandemia. G1, Economia, Tecnologia, 29/04/2020,

https://g1.globo.com/economia/tecnologia/noticia/2020/04/29/eric-yuan-obilionario-criador-do-zoom-que-viu-sua-fortuna-se-multiplicar-durantepandemia.ghtml. Acesso em: 01 ago. 2020.

BEZERRA, Mariana Andrade e CUNH JUNIOR, Moisés Ferreira. (2020) Cidades, espaços públicos e comportamento sobre o cenário urbano no contexto pandemia global. Observatório das Metrópoles, 11/06. Ver https://www.observatoriodasmetropoles.net.br/cidades-espacos-publicos-ecomportamento-discussoes-sobre-o-cenario-urbano-no-contexto-de-pandemia-global. Acesso em: 02 ago. 2020.

BIBLIOTECA DE MANGUINHOS (s/d). Gripe. Rio de Janeiro, Fio Cruz, Rede de Bibliotecas da Fio Cruz, In 
http://www.fiocruz.br/bibmang/cgi/cgilua.exe/sys/start.htm?infoid=96\&sid=106. Acesso em: 27 jul. 2020.

BOLOGNA, Mauro e AQUINO, Gerard (2020). Deforestation and world population sustainability: a quantitative analysis. Nature research, Scientific reports, 10/7631, 2020 .

CHERNILO, Daniel (2020), La crisis del virus corona Breve historia del desanclaje entre globalización, sistema internacional y estados-nación. Fios do Tempo (Ateliê de Humanidades), 26 de marzo. Disponible en: https://ateliedehumanidades.com/2020/03/26/fios-do-tempo-la-crisis-del-viruscorona-breve-historia-del-desanclaje-entre-globalizacion-sistema-internacional-yestados-nacion-por-daniel-chernilo/

EL PAIS (2020). El futuro depués del coronavirus. El País. In https://elpais.com/especiales/2020/coronavirus-covid-19/predicciones/.Acesso em: 01 ago. 2020.

FGV. (2020) Impacto econômico da covid 19. Propostas para o Turismo Brasileiro. Rio de Janeiro: Fundação Getúlio Vargas, abril

FIOCRUZ. (2020) Qual a origem desse novo coronavirus? FioCruz, 24/06 In https://portal.fiocruz.br/pergunta/qual-origem-desse-novo-coronavirus. Acesso em: 27 jul. 2020.

FU LEE, Kay. (2019) Inteligência artificial. Como os robôs estão mudando o mundo, a forma como amamos, nos relacionamos, trabalhamos e vivemos. Brasil, Rio de Janeiro: Globo Livros.

GORMLEY, Michael (2020). After the virus: more working at home, fewer but better friends. Newsday, april 6, In https://www.newsday.com/news/health/coronavirus/coronavirus-future-changesfuturists-1.43635849?utm source=tw nd . Acesso em: 29 jul. 2020.

JORNAL NACIONAL. (2020) Rússia anuncia vacinação em massa contra a covid 19 em outubro. G1, 03/08.

LEITÃO, Miriam. (2020) Economia global em escombros. Política hoje, O Globo, 01/08.

LINHARES, Maria Beatriz Martins e FLORIM, Sonia Regina (2020). Psicologia sobre efeitos da pandemia COVID-19 no desenvolvimento infantil. Estudos de Psicologia, Campinas, 37. Ver https://www.scielo.br/pdf/estpsi/v37/1982-0275-estpsi-37e200089.pdf.

MARTELO, Alexandre. (2020). Em carta ex-ministros da Fazenda defendem retomada da economia com o ambiental. G1, Economia, 14/07.

NASCIMENTO, Flavia. (2020) Coronavírus: casos de violência doméstica crescem 50\% durante o isolamento social. Entrevista. Radio EBC, 26 março. Disponível em 
https://radios.ebc.com.br/tarde-nacional-rio-de-janeiro/2020/03/coronavirus-casosde-violencia-domestica-crescem-50-durante-periodo-de. Acesso em 20. jul. 2020.

KAUFMAN, Martin e LEIGH, Daniel. (2020). Os desequilíbrios da economia mundial e a crise da covid 19. International Monetary Fund - Blogs, 04/08. Disponível em: https://www.imf.org/pt/News/Articles/2020/08/04/blog-global-rebalancing-and-thecovid19-crisis.

MAGNELLI, André. (2020) Qué puede el apocalipsis? Desde a gran aceleración hasta la pandemia globalizada. Ateliê de Humanidades in Angelcos, Nicolás et al. "COVID-19: Tiempos críticos en tiempos de pandemia”. Cuadernos de Teoría Social 6 (11) (no prelo).

MELO, Clayton (2020). Como o coronavirus vai mudar nossas vidas: dez tendências para o mundo pós-pandemia. EL PAÍS, 13 abril, in ${ }^{1}$ https://brasil.elpais.com/opiniao/202004-13/como-o-coronavirus-vai-mudar-nossas-vidas-dez-tendencias-para-o-mundo-pospandemia.html. Acesso em: 30 jul. 2020.

MORIN, Edgar. (2020). Changeons de voie. França, Paris: Denoel, 2020.

O Globo. OMS lista 133 estudos contra a Covid 19. Brasil, Rio de Janeiro, 09/08/2020.

RAONY, Ícaro et al. (2020). Psycho-neuroendocrine-Immune Interactions in COVI-19: Potential Impacts on Mental Health. Front. Immunol. 11:1170.

doi:10.3389/fimmu.2020.01170 In https://www.frontiersin.org/articles/10.3389/fimmu.2020.01170/full. Acesso em: 08 ago. 2020.

RAWORTH, Kate. (2019) A economia donut. Uma alternativa ao crescimento a qualquer custo. Brasil, Rio de Janeiro: Zahar.

RINCON, Paul. Iter: world's largest nuclear fusion project begins assembly. $B B C N E W S$, Science and Environment, 28 july In

file:///Users/elimarnascimento/Desktop/Iter:\%20World's\%20largest\%20nuclear\%20 fusion $\% 20$ project $\% 20$ begins $\% 20$ assembly $\% 20-\% 20 \mathrm{BBC} \% 20$ News.webarchive. Acesso em: 05 ago. 2020.

SAKAMOTO, Leonardo. (2020). Milionários propõem taxar fortunas contra covid. Isso pegaria no Brasil? Uol, 14/07 In https://noticias.uol.com.br/colunas/leonardosakamoto/2020/07/14/milionarios-propoem-taxar-suas-fortunas-contra-covid-issopega-no-brasil.htm. Acesso em: 27 jul. 2020.

SAMPAIO, Livia. Mulheres brasileiras, isolamento e estado abusivo: sobreviveremos? In AUGUSTO, Cristiane Brandão e SANTOS, Rogério Dultra dos. (2020) Pandemias e pandemônio no Brasil. São Paulo: Tirant lo Blanch.

SANJUÁN, Rafael; Nebot, Miguel R.; Chirico, Nicola; Mansky, Louis M.; Belshaw, Robert (1 de outubro de 2010). «Viral Mutation Rates». Journal of Virology (em inglês). 84 (19): 9733-9748. Acesso em: 03 ago. 2020. 
SANTIRSO, Jaime (2020). Corrida por uma vacina contra a covid 19 de acelera. El Pais, Pequin, 15 abril. In https://brasil.elpais.com/ciencia/2020-04-15/corrida-paraencontrar-uma-vacina-contra-a-covid-19-se-acelera.html. Acesso em: 31 jul. 2020.

SHARPLEY, Ricard. (2020) Tourism and sustainable development: exploring the theoretical divide. Journal of Sustainable Tourism, 28 (11), p. 1-5.

SILVER, Nate. (2013). 0 sinal e o ruído. Por que tantas previsões falham e outras não. Brasil, Rio de Janeiro: Intrínseca.

THOMPSON, Stuart A. (2020) How Long Will a Vaccine Really Take? The New York Times, Opinion, april 30. In https://www.nytimes.com/interactive/2020/04/30/opinion/coronavirus-covidvaccine.html._Acesso em: 08 ago. 2020.

TALEB, Nassin. (2008) A lógica do Cisne Negro. 0 impacto do altamente improvável. Gerenciando o desconhecido. Brasil, Rio de Janeiro: Best Seller.

WALLACE-WEELLS, David. (2019) A terra inabitável. Uma história do futuro. Brasil, São Paulo: Cia das Letras.

VEIGA, José Eli d. (2020). Chance Verde? Valor, 30 de julho, p. A17.

ŽIŽEK, Slavoj (2020). El coronavirus es un golpe al capitalismo a lo Kill Bill, p.23. In: Sopa de Wuhan: pensamiento contemporaneo en tiempos de pandemias/ Giorgio Agamben et al. Editorial ASPO (Aislamiento Social Preventivo y Obligatorio); 2020. 188 p. https://bit.ly/sopadewuhan. 